\title{
CRISTINA TRIVULZIO DI BELGIOIOSO, LA PRINCESA ITALIANA SOCIALISTA Y FEMINISTA
}

\section{CRISTINA TRIVULZIO DI BELGIOIOSO, THE SOCIALIST AND FEMINIST ITALIAN PRINCESS}

\section{Estela González de Sande}

Universidad de Oviedo, Oviedo, España

gonzalezestela@uniovi.es

Resumen: La princesa Cristina Trivulzio di Belgioioso es una de las figuras más relevantes del Risorgimento italiano en el plano político, social y cultural. Entre su legado figuran tratados filosóficos, ensayos político-históricos, textos literarios y numerosas contribuciones en periódicos franceses e italianos. Se trata, pues, de una mujer filósofa, historiadora, política, periodista y literata, cuya pluma se convirtió en pleno siglo XIX en arma contra las injusticias sociales, contra los gobiernos absolutistas o contra las desigualdades entre hombres y mujeres. Su enorme erudición y determinación le granjearon el respeto y la admiración de prohombres y mujeres ilustres de la época, siendo ejemplo y modelo de un nuevo ideal de mujer, afín a la sociedad moderna y progresista a la que aspirará Italia tras la unidad nacional. Este estudio presenta un sucinto recorrido por su trayectoria vital y su compromiso político y social, así como un análisis de su aportación a la querella de las mujeres, con el objetivo de exponer el pensamiento político de la autora y sus ideales socialistas y feministas.

Abstract: Princess Cristina Trivulzio di Belgioioso, a philosopher, historian, politician, journalist, and writer, is one of the most relevant figures of the Italian Risorgimento in the political, social, and cultural panorama. Her work includes philosophical treaties, political and historical essays, literary texts, and numerous contributions published by French and Italian newspapers. She became an important figure who, in the $19^{\text {th }}$ century, fought against social injustices, absolutist governments and gender inequalities. She was admired by both illustrious men and women of the time, becoming a role model who inscribed the New Woman ideal, proper of the Italian modern and progressist society of the time. This study is an analysis of her political and social compromise, her critical thinking, and her socialist and feminist ideals. 


\section{Cristina Trivulzio di Belgioioso (1808-1871)}

La princesa Cristina Trivulzio di Belgioioso es una de las figuras más fascinantes que nos ha legado el Resurgimiento italiano. La "prima donna d'Italia", como la definió Carlo Cattaneo en una carta fechada el 12 de julio de 1860 dirigida a Gino Daelli (Cattaneo, 1956: 370), presume de ser una de las mujeres más singulares del siglo XIX, no en vano su vida y su obra han suscitado el interés de numerosos investigadores, especialmente a partir de 2011 con motivo de las celebraciones del 150 aniversario de la unificación italiana, momento en que se rememora la historia de los grandes protagonistas del Resurgimiento, entre ellos nuestra autora.

En las últimas décadas del siglo XIX su figura había sido ensombrecida, aletargada inexplicablemente por la crítica (Cfr. Arriaga, 2008: 11), aun siendo una de las mujeres más activas e influyentes en el plano político y social de su época. Sus obras, escritas en su mayoría en francés y publicadas en Francia, eran totalmente desconocidas para el público italiano ${ }^{1}$ de finales del siglo XIX y principios del XX. Los libros que rescatan su memoria se remontan a los albores del Novecientos, cuando se dan a conocer las primeras biografías ${ }^{2}$ de la escritora en Italia y fuera de Italia.

1. Algunas de sus obras no fueron traducidas al italiano hasta bien avanzado el siglo XX. Es el caso, por ejemplo, de Ricordi dell'esilio, publicado en italiano por primera vez en 1946 por el Istituto Editoriale Italiano, casi un siglo después de su publicación en lengua francesa (1850).

2. Entre los primeros biógrafos de la escritora destacan en Italia Raffaello Barbiera y Aldobrandino Malvezzi, y en ámbito internacional el amigo Augustin-Thierry en Francia y Remsen Whitehouse en EEUU. En la segunda mitad del siglo
Su estrambótica vida de viajera y peregrina, lo inusual de sus costumbres, su enorme erudición y vasta cultura, sus dotes para el arte y la literatura, su razonamiento filosófico o moral, su contribución a la expansión de los ideales garibaldinos y a la unidad nacional, hacen de ella una auténtica heroína romántica, una mujer de enorme modernidad en un tiempo en que pocas mujeres ocupaban la esfera pública.

Esta gran dama italiana del siglo XIX nace en Milán en el seno de una de las familias más adineradas y reputadas de Lombardía, los Trivulzio. Su linaje se une en 1824 al del príncipe Emilio Barbiano de Belgioioso, con el que contrajo matrimonio a los 16 años de edad. Recibió en su niñez una exquisita educación, propia de la aristocracia, y se empapó de los ideales resurgimentales de su padrastro, Alessandro Visconti d'Aragona y de su maestra Ernesta Bisi, pintora de renombre.

Sus ideas políticas y su participación activa en las guerras por la independencia le procuraron dos exilios, primero en Francia y después en Oriente.

XX sobresale la obra de Severgnini. No obstante, estas obras se centran principalmente en la atípica existencia de la princesa, descuidando en cierta medida el estudio riguroso de su pensamiento y su producción científica y literaria. Vid. Barbiera, R., La principessa di Belgiojoso, i suoi amici e nemici, il suo tempo, Treves, Milán, 1902; Barbiera, R., Passioni del Risorgimento. Nuove pagine sulla Principessa Belgiojoso e il suo tempo con documenti inediti e illustrazioni, Treves, Milán, 1903; Malvezzi, A., Cristina di Belgiojoso (3 vols.), Milán, Treves, 1936-1937; Thierry, A., Une hérö̈ne romantique. La princesse Belgiojoso, Librairie Plon, París, 1926; Whitehouse, H. R., A Revolutionary Princess. Christina Belgiojoso Trivulzio Her life and times, E.P. Dutton, Nueva York, 1906; Severgnini, La principessa di Belgiojoso, Virgilio, Milán, 1972. 
Tenaz y fiel en sus convicciones, no cesó nunca de escribir, actividad que inició con 34 años de edad y que continuó hasta sus últimos días. Convirtió su pluma en el arma más idónea para defender su pensamiento e ideales: extinguir la dominación extranjera en Italia, contribuir socialmente al bienestar de la población italiana, implantar una sociedad más justa y paritaria y reivindicar el puesto que las mujeres se merecen en la Historia, temas recurrentes en su producción.

\section{El pensamiento político y feminista de Cristina Trivulzio}

Los primeros años del siglo XIX fueron convulsos en Italia, la derrota del imperio napoleónico y la resolución del Congreso de Viena en 1815 restituirá el poder del imperio austríaco de los Habsburgo y de las antiguas monarquías. No obstante, la conciencia de un pueblo italiano ya se había gestado y las ideas románticas calaban en la población, alentadas por reputados intelectuales como Alessandro Manzoni que se dirigían a la nación italiana como "una de armas, de lengua, de altar - de memorias, de sangre, de corazón" (Manzoni, 1848). A partir de 1820 tendrán lugar en Italia importantes movimientos insurgentes contra la dominación extranjera, siguiendo la estela del motín español de 1820. Jugará un papel fundamental la Carbonería, asociación secreta contraria a los regímenes absolutistas que surge en Nápoles y se extiende rápidamente por otras zonas de la península itálica. De las ideas carbonarias se embebe nuestra autora, de ahí el apelativo de "jardinera", nombre que reciben las mujeres afines a la Carbonería. A finales de los años 20, su amistad con algunas patriotas como Tere- sa Doria o Bianca Milesi Mojon, a quienes conoce en Génova, había despertado las sospechas de la policía austríaca y estaba bajo vigilancia. En 1829 viaja a Roma y entabla amistad con Ortensia de Beauharnais, cuyo salón frecuentaban los personajes más importantes de la Carbonería romana. Alli entró en contacto con otras "jardineras" como Hortense Allart, Anna Woodcock y Teresa Guiccioli.

Fiel seguidora de los postulados de Mazzini, sufraga y sostiene públicamente los movimientos carbonarios, lo que le acarrea el exilio a Francia en 1831.

Perseguida y vigilada por la policía austríaca, en 1830 huye a Génova y de ahí a Suiza. A pesar de la orden de repatriación que pesa sobre ella, conseguirá llegar al país galo. Sus bienes, sin embargo, serán confiscados por el gobierno austríaco, acusada de prófuga y de desleal al imperio.

En Francia transcurre casi diez años de su vida, convirtiéndose en una de las figuras más relevantes de la política y la cultura parisinas. Su casa de París acogerá a intelectuales, filósofos, historiadores y políticos de renombre, como Henri Martin, Augustin Thierry, François Mignet, Balzac, De Musset, Georges Sand, Cousin, el general La Fayette o Adolphe Thiers. También a los patriotas italianos exiliados, entre ellos Vincenzo Gioberti, Terenzio Mamiani, Carlo Poerio, Francesco Orioli, Pellegrino Rossi, Camillo Benso Cavour, Giuseppe Massari, Silvestro Leopardi, Michele Amari o Roberto Ferrari ${ }^{3}$.

3. Disponemos de numerosos documentos que testimonian su relación con estos personajes, pues no sólo se conserva gran parte de su correspondencia epistolar, sino que ella misma dejó huella de sus amistades y relaciones en varias de sus obras, especialmente en su Souvenirs dans l'exil (Recuerdos del exilio), publicado por fascículos en el periódico francés Le National en 1850. 
Dos años después del nacimiento de su única hija, en 1840, regresa a Italia y se instala en la casa familiar de Locate, donde funda una pequeña explotación agrícola en la que pretende poner en práctica las teorías de Saint-Simon y de Charles Fourier, precursores del socialismo. Cristina Trivulzio crea en su propia casa una especie de falansterio y se esfuerza por difundir este modelo fuera de Locate, aunque sin éxito. La princesa se interesa por las condiciones de trabajo de los campesinos y por su retribución e, incluso, los anima a crear asociaciones, preanunciando el sindicalismo ${ }^{4}$. Se preocupaba, además, por los hijos de los campesinos, niños que vivían en la absoluta pobreza y analfabetismo. Por ello, crea escuelas para los más pequeños, talleres agrícolas para la formación de los jóvenes, centros de enseñanza femenina, y se convierte en benefactora de los habitantes de Locate ${ }^{5}$.

En esta época inicia su fecunda actividad de escritora con el fin de promover y difundir sus ideas y su pensamiento político y social. Y lo hace precisamente con un polémico ensayo titulado Essai sur la formation du dogme catholique, publicado

4. Sobre la influencia del socialismo propugnado por Fourier en Cristina Trivulzio véase Giuseppe Santonastaso, Il socialismo fourierista di Cristina di Belgiojoso, Rivista internazionale di filosofia política e sociale, fasc II, abril-junio, 1963, pp. 126-137.

5. Ferrante Aporti publica en 1846 un artículo que recoge la labor social de la princesa de Belgiojoso en estos años, con información sobre los centros educativos que promovió en Locate con "intelligentissima carità": Vid. Aporti, F., "Istituzioni di comune educazione e soccorso fondate in Locate (provincia di Milano) dalla contessa Cristina Trivulzio principessa Belgiojoso", en Annali universali di statistica, vol. IX, agosto de 1846, p. 169-179. Artículo digitalizado en http://www. cristinabelgiojoso.it/articoli/FerranteAporti.pdf. en París en $1842^{6}$, bajo "la incomprensión y el rechazo del ambiente milanés, que no demuestra mucho aprecio por una mujer progresista, independiente y, además, filósofa, que es como se da a conocer con sus primeros escritos" (Arriaga, 2011: 10). Se trata de una obra de carácter teológico-filosófico sobre el origen del dogma católico y su repercusión en la sociedad. Un texto inaudito para la pluma de una dama aristócrata, de gran extensión (4 volúmenes) y bien fundamentado, que desmonta los prejuicios contra la escritura femenina, dando muestras de la capacidad de las mujeres para afrontar temas filosóficos. La autora analiza y estudia la historia del catolicismo y sus preceptos, poniendo en entredicho algunas argumentaciones de los grandes Padres de la Iglesia que han sentado las bases de la cultura cristiana e instando al progreso y a la regeneración del cristianismo.

Dos años después traduce al francés la Scienza Nuova del filósofo Giambattista Vico, que se publica en París en 1844. Trivulzio pretende dar a conocer al público francés las tesis de Vico y de nuevo dar muestras de su erudición, interesándose por una obra de tal complejidad.

Ese mismo año inicia su colaboración con el periódico La Democratie Pacifique que funda y dirige el discípulo de Fourier, el economista Victor Considerant ${ }^{7}$. Sus escritos en el periódico francés versarán fundamentalmente sobre la situación de

6. El texto se conserva solo en francés, nunca se ha llevado a cabo su traducción al italiano.

7. Sobre la relación con Victor Considerant, véase Gianna Proia, Cristina di Belgiojoso e Victor Considerant: una principessa liberale ed un socialista fourierista, en Cristina di Belgiojoso: politica e cultura nell'Europa dell'Ottocento, Ginevra Conti Odorisio, Cristina Giorcelli, Giuseppe Monsagrati, Loffredo University Press, 2010, pp.287-306 
Italia y su población, con especial atención a la región de Lombardía.

En 1845 adquiere La Gazzetta italiana, periódico que un año más tarde será censurado y prohibido por el gobierno austríaco. En él se difunden las ideas liberales de los patriotas italianos. Tras el cierre de la Gazzetta funda en París la revista L'Ausonio, con el subtítulo "Rivista italiana", que dirigirá hasta 1848 . El número inaugural se abre con un texto de Trivulzio titulado "Stato attuale dell'Italia" en el que preanuncia el objetivo de la revista:

Questa pubblicazione essendo destinata a far conoscere sì agli Italiani che agli stranieri la condizione di questa nostra contrada, onde nell'esaminare le piaghe rintracciate ad esse rimedio e ristoro, sembrami che giovi l'esporre in sulle prime un quadro esatto e succinto dello stato attuale dell'Italia sotto ogni suo aspetto, un ragguaglio cioè della condizione morale, politica, amministrativa, finanziaria di questo paese. Nè ciò basta, chè per far ben nota una contrada a coloro che in quella non nacquero (e sgraziatamente gli Italiani sono gli uni verso gli altri nella situazione dello straniero verso lo straniero), conviene riandare più addietro nelle cose, e discorrere brevemente delle origini, poi trattare della popolazione, del carattere di lei fisico e morale, del grado di coltura morale a cui è giunta, dei lavori ed industrie cui accudisce, degli studii ai quali attendono le classi degli abitanti più alte; di tutte quelle materia insomma che compongono la nazione in qualità di individuo, che vuol dire ne delineano il carattere e ne spiegano $\mathrm{i}$ destini (Trivulzio, 1846: 5).

Así pues, L'Ausonio nace para dar a conocer a los italianos y a los extranjeros la situación de Italia en todos sus ámbitos: político, moral, social, financiero, etc. Serán frecuentes las aportaciones de Cristina a la revista denunciando las condiciones socia- les de los campesinos, la censura en la cultura y el arte por parte del poder austríaco o la expoliación de los territorios italianos.

Como suplemento a L'Ausonio se publica en Milán, de abril a julio de 1848, 41 números de // Crociato, un periódico político como reza el subtítulo, que presenta una crónica de los acontecimientos políticos del país en las distintas ciudades italianas, difundiendo el liberalismo y animando a los italianos a luchar por la unidad nacional. En su primera página se apunta que el objetivo será conseguir "la felicidad, la fuerza y la grandeza" de la patria italiana: "Le parole che noi adottiamo oggi ad esprimere i principii che all'Italia sembrano ora più che ogni altro necessarii sono: Indipendenza; libertà; unità; democracia" (// Crociato, 1848: 1)

En estos años inicia su colaboración con la prestigiosa revista francesa Revue de Deux Mondes, desde cuyas páginas narra episodios de la historia reciente de Italia ${ }^{8}$.

Como sostiene Arriaga Flórez "la princesa milanesa es una de las primeras intelectuales en darse cuenta de la importancia de la propaganda política a través de los

8. Del 15 de septiembre de 1848 al 1 de enero de 1849 la Revue de Deux Mondes publica cuatro artículos de Cristina Trivulzio en lengua francesa que giran en torno a la cuestión histórico política de Italia en 1848, narrando episodios bélicos de los movimientos insurgentes en distintas zonas de Italia: 'L'Italie et la révolution italienne de 1848: Insurrection milanaise. Le gouvernement provisoire. Les corps auxiliares", "L'Italie et la révolution italienne de 1848: La guerre de Lombardie. La siège et la capitulation de Milan", "L'Italie et la révolution italienne de 1848: La révolution et la république de Venise", "L'Italie et la révolution italienne de 1848: La guerre dans le Tyrol italien". Los artículos se pueden leer y descargar en la web dedicada a Cristina Trivulzio, creada por Sandro Fortunati: https://www. cristinabelgiojoso.it/wp/biblioteca/ 
periódicos o revistas" (Arriaga, 2011: 11). Con su actividad periodística, además, formará parte de la primera generación de escritoras que hacen del periodismo su profesión como Caterina Percoto, Erminia Fuà Fusinato, Luigia Codemo o Luisa Amalia Paladine (Cfr. Arriaga, 2011: 13).

En 1850 participa en la fundación de otro periódico, La croce di Savoia, que se convierte en portavoz de los liberales meridionales, muy atentos al debate político de los acontecimientos del norte de Italia.

Cabe señalar que en el bienio de 1848 a 1850 se producen importantes movimientos insurreccionistas en los estados italianos contra los gobiernos absolutistas, especialmente contra la dominación habsbúrgica. En el Véneto se declaró la República de San Marco y el pueblo de Milán se sublevó en la conocida como "las cinco jornadas de Milán" encabezadas por Gabrio Casati. Con el apoyo de Carlos Alberto de Saboya, rey del Reino de Cerdeña y de Piamonte se consiguió vencer a los austríacos en territorio lombardo, aunque inmediatamente después recuperarían sus dominios. Los estados pontificios y el Reino de las dos Sicilias también se rebelaron y en Roma se consiguió instaurar la fugaz "República romana", dirigida por Giuseppe Mazzini, Carlo Armellini y Aurelio Saffi. Estas revueltas, que pronto fueron sofocadas por los ejércitos extranjeros, constituyen la primera guerra por la independencia italiana y en ella la princesa de Belgioioso estará en primera línea. Cuando conoce la insurrección de Milán, Cristina Trivulzio se encuentra en Nápoles, donde prepara un batallón de hombres armados con el que se dirige inmediatamente a la ciudad de Milán (Severgnini, 1972: 117).

Cuando se proclama la República romana, Trivulzio será la encargada de orga- nizar y dirigir los hospitales de la ciudad. Surge, así, la primera asociación de mujeres para la asistencia de los heridos de guerra, con un comité de dirección encabezado por la Belgioioso, junto a Marietta Pisacane y Giulia Bovio Paolucci, según el edicto publicado el 27 de abril de 1849 por el gobierno de la República "alle don-

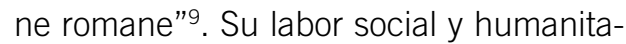
ria será interpretada en años posteriores como germen de la "Croce Rossa" (Cruz Roja), asociación reconocida en Italia como entidad pública en 1884.

El asedio a Roma por parte de las potencias europeas y en particular del ejército francés comandado por Luis Napoleón Bonaparte puso fin el 4 de julio de 1849 a la República romana, después de meses de luchas en las que intervinieron franceses, españoles y austríacos. El pontífice Pío IX recuperó el control de los estados Pontificios entre los que se incluía la ciudad de Roma.

Los colaboradores de Mazzini y Garibaldi tuvieron que abandonar precipitadamente la ciudad, entre ellos, Cristina Trivulzio, que se había implicado política y económicamente en la prosperidad de la joven República.

El 31 de julio de 1849, tras recibir una carta anónima en la que se le informa de que había sido acusada de "sentimenti irreligiosi" y que está bajo sospecha del cardenal Antonelli, embarca en el buque "Mentor" que parte de Civitavecchia rumbo a Malta. Comienza aquí su segundo exilio, un peregrinaje de la escritora que culminará en Oriente. De Malta se traslada a Grecia donde vivirá algún tiempo. De allí viajará a Constantinopla y a la península

9. El llamamiento "Alle donne romane" se puede leer íntegro en http://www.donneconoscenzastorica.it/vecchio/testi/trame/assistenzadoc. htm\#donne 
de Anatolia para finalmente instalarse en el valle de Eiaq-Maq-Oglu, donde compra un terreno que dedicará a la explotación agrícola. En enero de 1852 emprende un viaje a caballo hacia Jerusalem, atravesando Siria y Palestina. Le acompaña su hija María, que por aquel entonces cuenta con 14 años, y una pequeña cohorte de sirvientes y guías locales.

A partir de este momento comienza la redacción de una serie de obras de carácter literario, partiendo de sus autobiográficos Recuerdos del exilio.

Su compromiso político y social no cesará durante sus años de exiliada, pero sí tomará un rumbo diverso. Es el momento en que se acrecienta la atención de Trivulzio a las mujeres y a la condición femenina, especialmente durante sus viajes por los países árabes. Durante el tiempo transcurrido en Turquía (de 1850 a 1855) se embebe de la cultura árabe, del mundo campesino, de las tradiciones y costumbres de Oriente que tanto disuenan de las de Occidente. Aprende a amar la tierra en la que vive y a transformar sus vicisitudes en páginas literarias. Sus escritos, enviados con puntualidad a la prensa francesa, no solo contribuirán a sostener su economía, serán también altavoz para la difusión de una nueva e inédita visión del mundo árabe al lector occidental. A este cometido se entregará por completo durante su estancia en Asia: a transmitir su propia visión de Oriente y sus experiencias personales en cada uno de los recónditos lugares que visitará ${ }^{10}$.

10. Los viajes por Oriente de Cristina Trivulzio y su visión del mundo árabe, con especial atención a la imagen del harem y de las mujeres musulmanas, ha suscitado numerosos estudios por parte de la crítica. Este argumento ha sido analizado en diferentes libros y artículos entre los que citamos Scriboni, M., "Il viaggio al femminile in
De regreso a Italia, en 1856 continuará su actividad de escritora y periodista. En 1860 funda un periódico francés en Mi-

Oriente nell'800: la principessa di Belgiojoso, Amalia Solla Nizzoli e Carla Serena”, en Annali d'Italianistica, vol. 14, Luigi Monga, 1996; Scriboni, M., "Se v'avessi avuto per compagna...". Incontri tra donne nelle lettere e negli scritti dall'Oriente di Cristina Trivulzio di Belgiojoso", en Italian Culture, vol. XII, 1994; Arriaga Flórez, M., "Cristina Trivulzio di Belgiojoso: viaje y exilio", en El tema del viaje: un recorrido por la lengua y la literatura italiana, Universidad de Castilla La Mancha, Cuenca, 2010, pp. 389400; Arriaga Flórez, M., "viajeras italianas entre oriente y occidente", en Relatos de viajes, miradas de mujeres, Ediciones Alfar, Sevilla, 2007, pp. 37-48; Marcillas Piquer, I., "Literatura de viajes en clave femenina: los pre-textos de Aurora Bertrana y otras viajeras europeas", en Revista de Filología Románica, vol. 29, núm. 2, 2012, 215-231; Marcillas Piquer, I.,"La visión del harén en la prosa de las viajeras europeas: entre la seducción y el rechazo. El caso especial de Aurora Bertrana (1892-1974)", en Revista de filología románica, n.32, 2015, pp. 225-238; Ricaldone, L., 'Uscire dall'Occidente. Donne e harem nelle esperienze di viaggio di Amalia Nizzoli, Cristina di Belgiojoso e Matilde Serao", en $D W F$, n. 1-2, 2000, pp. 54-73; Fabris Grube, A., "Una principessa italiana in Turchia: Cristina Trivulzio di Belgioioso", en La conoscenza dell'Asia e dell'Africa in Italia nei secoli XVII e XIX, Istituto Universitario Orientale, Nápoles, 1984; Ricorda, R., "In viaggio tra Occidente e Oriente: Cristina di Belgiojoso scrittrice e saggista", en With a pen in her hand. Women and writing in Italy in the Nineteenth Century and beyond, The Society for Italian Studies, Leeds, 2000; Giuli, P., "Cristina di Belgioiso's Orient, en Nemla Italian Studies, n. 15, 1991, pp. 129-150; Michelacci, 1., "Cristina Trivulzio di Belgioioso allo specchio dell'Oriente", en Lettere italiane, n.66,4, 2014, pp. 580-595; Spackman, B., "Hygiene in the Harem: The Orientalism of Cristina di Belgioioso, $M L N$, n.124, 2009, pp. 158-176; Maldini Chiarito, D., "Gli scritti della vecchiaia", en «La prima donna d'Italia» Cristina Trivulzio di Belgiojoso tra politica e giornalismo, Franco Angeli, Milán, 2010, pp. 193-219. 
lán: L'Italie y retoma su actividad política en pro de la unificación italiana, que se hará efectiva en 1861. En la década de los 60 publica Historie de la maison de Savoie (París, 1860) y sus Osservazioni sullo stato attuale dell'Italia e sul suo avvenire (1868).

También de esta década será su ensayo Della presente condizione delle donne e del loro avvenire (1866), un texto aún poco conocido, pero de gran valor histórico para la querella de las mujeres, un verdadero manifiesto del pensamiento feminista de nuestra autora.

\section{De la presente condición de las mujeres y de su futuro}

El debate sobre la situación de las mujeres y la reivindicación de sus derechos se fragua y adquiere vigor a raíz de la expansión por Italia de los ideales de la Revolución francesa y la invasión de Napoleón Bonaparte en territorio italiano, que dio lugar a la deposición de los regímenes monárquicos y a la instauración de repúblicas "hermanas"11 en el denominado Trienio jacobino (1796-1799). Esta época se caracteriza por el espíritu reformista en pro de los derechos humanos bajo la máxima de libertad, igualdad y fraternidad. En ese

11. En 1796 Napoleón Bonaparte invadió el norte de Italia, venciendo al ejército piamontés y austríaco. En junio de 1797 se creó la República Cisalpina (con capital en Milán y formada por la Lombardía austríaca, Módena, Reggio, los territorios pontificios de Ferrara y Rávena y las provincias de Bérgamo y Brescia) y la República Ligúrica que sustituía a la anterior República de Génova. En 1798 se proclamó la República romana y se anexionó el Piamonte a Francia. En 1799 se creó la República napolitana y el ejército francés ocupó la Toscana. momento se alza la voz de muchas mujeres que toman parte en la vida pública y política del país, a través de proclamas, discursos o textos que reivindican el papel de las mujeres y su lugar en la sociedad igualitaria que se pretende diseñar. De entre ellos destaca el tratado de Rosa Califronia Breve Difesa dei diritti delle donne (1794) ${ }^{12}$ o los discursos de 1797 La causa delle donne, atribuido a la veneciana Annetta Vadori y Della schiavitù delle donne de Carolina Lattanzi ${ }^{13}$. Estos textos suponen un punto de partida esencial en el debate sobre la cuestión femenina que se avivará a lo largo del siglo XIX en Italia y fuera de Italia, y que se intensifica una vez conseguida la unidad nacional, momento en que se hace necesaria la puesta en marcha de reformas, entre éstas la implantación de un nuevo código civil o la regulación de la educación y de la lengua. Precisamente el acceso a la educación por parte de las mujeres será uno de los temas más recurrentes que encontramos en las obras de mediados del siglo, como las de Caterina Franceschi Ferrucci Della educazione morale della donna italiana (1847) y Degli studii delle donne (1853) o la de Giulia Molino-Colombini Pensieri e lettere sulla educazione della donna in Italia (1851).

A partir de 1861 a los escritos que reivindican la educación femenina, se suman los que apuestan por la emancipación y

12. Traducido al español por Mercedes González de Sande, con una extensa edición crítica: Breve defensa de los derechos de las Mujeres, Arcibel, Sevilla, 2013.

13. Para mayor información sobre los discursos de las mujeres italianas en el trienio jacobino véase Milagro Martín Clavijo, "La causa delle donne" y los derechos políticos de las mujeres durante el trienio jacobino italiano, Revista Internacional de Culturas y Literaturas, abril 2014. 
los derechos universales de las mujeres. En este campo destaca Anna Maria Mozzoni con su obra La donna e i suoi rapporti sociali (1864) donde pone de manifiesto el papel desempeñado por las mujeres durante el Resurgimiento y su valía en la esfera pública. Un año después pide el reconocimiento de los derechos de las mujeres en el nuevo código civil en la obra La donna in faccia al progetto del nuovo Codice civile italiano (1865) en el que sostiene "l'affermazione dei diritti della donna, in principio, è oggi voluta dallo spirito delle masse, e questo principio si è già incarnato nei costumi di tutti i popoli civili. Se l'uomo rappresenta la famiglia negli affari, la donna la rappresenta nella società" (Mozzoni, 1865: 4).

En 1866 Mozzoni firma Un passo avanti nella cultura femminile. Tesi e progetto, el mismo año que Enrichetta Caracciolo escribe la Proclama alle Donne d'Italia y se publica Della presente condizione delle donne de Cristina Trivulzio.

El texto de la Belgioioso ve la luz en el primer número de la revista florentina Nuova Antologia, fundada por Francesco Protonotari. Una revista que se convertirá en referente de la cultura italiana y que perdurará hasta nuestros días.

En tan prestigioso escenario presenta la princesa sus postulados sobre la condición de las mujeres y sobre su futuro, animada, como ella sostiene, por personas reputadas -y que respeta- a expresar su punto de vista.

La obra se abre con la afirmación categórica de la igualdad intelectual entre hombres y mujeres:

Que la mujer no es ni moral ni intelectualmente inferior al hombre, sólo en la acción ejercitada por el físico en la moral y en el intelecto, o incluso por los efectos de la edu- cación, hoy en día es algo generalmente reconocido y admitido. Pero algunos se asombran, sin embargo de que, a pesar de tal igualdad entre la parte espiritual de la mujer y la del hombre, la mujer se haya quedado siempre y se quede todavía en una condición social inferior a la del hombre" (Trivulzio, 2011: 55)14.

La autora parte del origen de la desigualdad, que atribuye a épocas ancestrales cuando primaba la fuerza por encima de la razón. La sumisión femenina se ha mantenido desde entonces y perpetuado en la cultura de las civilizaciones modernas. Evidencia cómo en las poblaciones más atrasadas es donde peor tratada es la mujer, afirmando implícitamente que una sociedad moderna no debe aceptar tal estado de inferioridad.

La condición inferior de la mujer fue establecida desde la más remota antigüedad, y cuando se estableció estaba fundada en la verdad; ya que en aquel tiempo de absoluta barbarie, no se apreciaba ni se estimaba otro valor que el físico y, físicamente considerada, la mujer es indudablemente y necesariamente inferior por fuerza y por resistencia al hombre. Basta observar los usos y las costumbres actuales de las poblaciones bárbaras aún existentes, para encontrar a la mujer considerada y tratada como una esclava y como apéndice del hombre, sin consideración alguna a la naturaleza, a las necesidades, a los deseos, a los derechos de ésta (Trivulzio, 2011: 57).

En este sentido, la escritora presenta "la historia de la Humanidad como un itinerario que asocia la evolución de una so-

14. Para las citas remitimos a la obra traducida al español, De la presente condición de las mujeres $y$ de su futuro (Arcibel Editores, Sevilla, 2011), con estudio crítico introductorio de Mercedes Arriaga Flórez y traducción de Estela González de Sande. 
ciedad con la liberación de la mujer de su estado de esclavitud" (Arriaga, 2011: 25). Como sostiene Arriaga, el cambio de la situación de las mujeres va emparejado al progreso, una idea que resonaba cada vez con más fuerza en otras mujeres y hombres de la época, y que encontraremos de forma explícita en la obra del filósofo inglés John Stuart Mill La schiavitù delle donne (1869) ${ }^{15}$.

En su discurso se plantea varias cuestiones, entre ellas por qué se ha perpetuado el estado de inferioridad de la mujer incluso en las civilizaciones más avanzadas:

La civilización un día apareció, y la interminable empresa de reparar las ofensas hechas, las monstruosas injusticias cometidas por los unos, y sufridas por los otros, comenzó. Pero este albor de civilización no surge sino muchos siglos después de la primera fundación de una sociedad cualquiera, pues todavía en la Edad Media se consideraba la fuerza física superior a cualquier otra potencia. En el transcurso de tantos siglos la mujer había sido más o menos esclava del hombre; el hombre, que desde el origen de la sociedad había declarado la inferioridad de la mujer y el deber de ser sometida, no se preocupaba de tenerle que conceder igualdad y libertad. Quizá la mujer podía protestar contra la usurpación, y reivindicar sus derechos; pero la propia mujer había aceptado su impuesta condi-

15. Título original The Subjection of Women, traducido al italiano con el título La schiavitù delle donne y recientemente como La servitù delle donne. Un ensayo de gran valor documental, testimonio de la implicación de los hombres en la querella de las mujeres. La crítica actual ha determinado que compartió la autoría con su mujer, la también filósofa Harriet Taylor. El texto, que denunciaba el estado de sumisión de las mujeres y exigía el reconocimiento de sus derechos, tuvo gran repercusión en toda Europa. ción, se había acomodado a ella y había llegado a preferirla (Trivulzio, 2011: 57).

Trivulzio afirma en más de una ocasión que son las propias mujeres las que han aceptado la desigualdad y lo achaca a varios factores: por una parte a la imagen femenina que ha proyectado la cultura patriarcal, que hizo creer a las mujeres que su objetivo en la vida era "gustar al hombre" y, para ello, debía ser totalmente diferentes a ellos. Y, por otra parte, a la imposición de la diferencia en el intelecto: la mujer, para distinguirse del hombre, debía ser ignorante.

Para reconciliar a las mujeres con su inferioridad, los hombres, movidos por maldad o por instinto natural, han llevado a cabo un artificio singular. Después de haber persuadido a las mujeres de que el colmo de su gloria consiste en el gustar a la gran mayoría de ellos, en el gustar más gratamente y más largamente, los hombres se dispusieron a convencerlas de que su simpatía no se podría obtener si no se mostraban del todo diferentes a ellos. El vil es despreciado, avergonzado, porque al hombre se le pide coraje; pero esta virtud no está permitida a la mujer que busca la admiración del hombre. Los sabios, los científicos, los poetas, los hombres de Estado, etc., gozan del respeto universal, mientras que el ignorante y el ocioso son ridiculizados y no tenidos en cuenta. Pero a la mujer se le pide expresamente la más perfecta ignorancia: y ¿quién no conoce los ridículos sobrenombres puestos a las mujeres cultas, el deplorable efecto de un bonito dedo manchado de tinta, etc., etc.? Los hombres convencieron a las mujeres de que su admiración, su afecto era a costa de su inferioridad intelectual, y las mujeres así lo han creído, y hay cultas que escondían su cultura por temor a ser incluidas entre las mujeres superiores, las pedantes, y otras similares abominaciones (Trivulzio, 2011: 59). 
Tales aseveraciones calaron en la conciencia femenina y masculina de tal manera que las mujeres que mostraban una inteligencia superior eran reprobadas y vituperadas. Por ello, muchas se avergonzaban 0 escondían sus dotes intelectuales.

Las mujeres con algo de ingenio se apropian fácil y rápidamente de cualquier noción que se les presente. Y sin embargo, cuántas veces habréis oído a estas mismas mujeres declararse del todo ineptas para los más fáciles estudios, cuando éstos son considerados (y no sé por qué) como enfocados particularmente a la naturaleza del viril ingenio $[\ldots]$ Y todo ello porque los hombres han convencido a las mujeres de que tales estudios, que son por otra parte el ejercicio más saludable del intelecto, están destinados sólo a ellos, y mancharían indeleblemente la hermosura y las gracias femeninas (Trivulzio, 2011: 61).

La educación para nuestra autora se convierte en el pilar fundamental para el cambio de mentalidad. Es necesario formar a las mujeres, instruirlas en educación superior, abrirles las puertas de universidades y academias...solo así podrán algún día hacer valer sus cualidades y solo así se iniciará el camino de una sociedad paritaria. La escritora exhorta a las mujeres dotadas para los estudios a emprenderlos, a pesar de las dificultades, a entrar en las aulas y hacer los mismos exámenes, a ganarse con sus actos el respeto de los hombres y ser ejemplo para las generaciones futuras:

[...] las jovencitas abocadas a los estudios serios y elevados, podrían asistir a las aulas de los colegios e institutos, si estuvieran realmente animadas por el deseo sincero de instrucción y si observaran una tranquila y modesta compostura; y creo que al salir de esas escuelas, preparadas para hacer dignamente los mismos exámenes que les ponen a los jóvenes, no encontrarían des- pués ningún impedimento para asistir a los cursos públicos que componen la educación universitaria. No digo que la primera joven que se presentara a tales pruebas pudiera aprobarlas sin estar dotada de mucho valor, de sangre fría, de una invencible perseverancia y de fuerzas intelectuales de primer grado: pero ninguna conquista puede hacerse sin un conquistador, y los conquistadores, a cualquier época o sexo que pertenezcan, siempre son criaturas excepcionales (Trivulzio, 2011: 77).

Esta conquista del espacio masculino se hace imprescindible para alcanzar el cambio. La idea de la princesa es que la sociedad deje de aceptar como virtud femenina la ignorancia y, para ello, es necesario que las mujeres demuestren que son intelectualmente iguales al hombre. De esta manera, se abrirían para ellas escuelas femeninas donde podrían recibir la misma educación que reciben sus coetáneos varones.

Después, cuando la difícil prueba obtuviera un discreto éxito, rápidamente sería repetida por otras jovencitas, hasta que siendo evidente para todos que las mujeres ya no se conforman con la ignorancia antigua y hacen felices intentos para salir de ella, se abrirían escuelas femeninas donde las mujeres recibirían la misma educación que hasta ahora ha sido privilegio de los hombres, sin que la convivencia entre estudiantes de distinto sexo pudiera dar motivo a escándalos y desconfianzas (Trivulzio, 2011: 79).

Para sostener su tesis presenta ejemplos de mujeres ilustres que destacaron en el pasado en las Ciencias y que recibieron las alabanzas de hombres y mujeres, entre ellas cita a Maria Gaetana Agnesi, una de las matemáticas más sobresalientes de la llustración:

¿Acaso nuestra Italia en el pasado no presume de muchas mujeres ilustres por 
ingenio y por conocimiento, algunas de las cuales ocuparon cátedras científicas en las universidades públicas, y especialmente en la de Bolonia? ¿Nuestra Agnesi no fue reconocida por su gran valía en las ciencias matemáticas, y acaso no recibió honores para despertar la emulación y no la rivalidad de los hombres de su tiempo? Y ¿por qué nuestra época se mostraría menos liberal que aquella? (Trivulzio, 2011: 79).

Se plantea por qué habiendo casos de mujeres excepcionales en el pasado se ha seguido afirmando la inferioridad del sexo femenino. En su opinión se debe a que esas mujeres no tenían conciencia de la importancia de sus acciones, saciaban su naturaleza intelectual sin ser conscientes de que podían sentar un precedente.

En casi todos los países civilizados fueron aceptadas por la sociedad muchas excepciones a la general insuficiencia de la mujer en las cosas de la mente, y sin embargo estas excepciones todavía no han debilitado la regla o, mejor dicho, la máxima de la inferioridad femenina. ¿Por qué? El porqué se vislumbra fácilmente. Las mujeres que se ilustraron en las ciencias, en las letras, o en las artes, han obedecido a su instinto, han satisfecho las necesidades de su mente, han seguido la impetuosa llamada de su naturaleza espiritual, pero sin proponerse otro fin que éste. Una mujer tuvo el honor de ocupar una cátedra universitaria; pero este caso sólo se repetiría después de un largo periodo de tiempo, o nunca. Aquella mujer había abierto la puerta a otras mujeres; pero ninguna pensó en aprovecharse, y la puerta se volvió a cerrar gradualmente por sí misma, de tal manera que quien le echa una mirada al pasar por delante, se da cuenta de que está cerrada con cerrojos y pestillos, y que abrirla es algo imposible (Trivulzio, 2011: 81).

Por ello, en numerosas ocasiones la Belgioioso se dirige directamente a las mujeres, las insta a abrir las puertas a otras mujeres, a preparar el camino hacia la futura igualdad.

La autora insiste mucho en la igualdad intelectual, pero deja claro que hombres y mujeres son distintos en muchos otros aspectos y que estas diferencias deben mantenerse. Su reivindicación se centra, por tanto, en el acceso a la educación y en el reconocimiento de las capacidades morales y cognitivas de las mujeres. Su texto, en este sentido, difiere del de otras mujeres como los de Mozzoni y las emancipacionistas (Cfr. Arriaga, 2011: 31).

Para desvincularse de la corriente feminista en boga en la segunda mitad del siglo XIX, declara con "malinconica rassegnazione" (Malvezzi, 1936-1937: 383) que los cambios no pueden ser radicales, sino progresivos, que es preciso partir de pequeñas transformaciones para conseguir empresas mayores en el futuro. Por ello, no comparte las peticiones de paridad total entre ambos sexos.

Las mismas mujeres que en los últimos tiempos han pedido lo que llaman la propia emancipación, a mi parecer, han hecho más que nunca difícil la satisfacción de sus deseos. Tanto en Francia como en Italia, los hombres cultos y muchas mujeres han evitado escuchar esas peticiones y se han indignado, no sólo con las autoras de ésas, sino también contra el objeto demandado. Se piden reformas radicales y rápidas, procedimientos y leyes que extrañamente disturbarían la paz de las familias, y que producirían en la sociedad una deplorable confusión (Trivulzio, 2011: 81).

De esta manera, Cristina se desmarca de posturas radicales y, aparentemente, del movimiento feminista, presentando una ideología más moderada e, incluso, conservadora, que contrasta completamente con sus actos y su forma de vida. Ella, 
que siempre fue una mujer libre en todos los sentidos (sin ataduras conyugales ni paternas ni financieras), sostiene que la mujer debe seguir ocupando su papel de madre y esposa, y que su libertad debe recaer única y exclusivamente en la educación, esa debe ser la única exigencia.

La misma palabra, tantas veces proferida en esas peticiones de mujer libre tiene, y no sin razón, un no sé qué de antipático y de disgustoso, que provoca la risa de los hombres, y la indignación de muchas mujeres. Que la mujer sea libre de educarse sólidamente y no puerilmente, que sea libre de tener la justa compensación por sus cansancios, el premio de su buen éxito, pero es mejor no pedir otras libertades (Trivulzio, 2011: 83).

Se trata de una postura conciliadora que, sin embargo, persigue un objetivo mucho más ambicioso del que podría advertir un lector medio de la época. Sabedora de las dificultades de una reforma integral de la condición de las mujeres y de la oposición que encontrarían tales reformas, se limita a proponer y reivindicar el acceso a la educación. Pero se vislumbra en su escrito la esperanza de un cambio más integral, más allá de la educación, para las generaciones venideras.

Conviene, sin embargo, caminar despacio, quitar una a una las piedras que puedan eliminarse en el actual edificio social, sin causar una ruina total; conviene, además, poner puntales resistentes con el fin de mantenerlo recto, mientras que se quitan las piedras que lo sustentan, y que se usan para la erección de un nuevo edificio, en el que las necesidades de todos y de todas, encuentren una ecuánime satisfacción. Las mujeres que ambicionan un nuevo orden de las cosas, tienen que armarse de paciencia y de abnegación, contentarse con preparar el suelo, sembrarlo, pero no pretender recoger la cosecha. La generación actual sólo puede preparar días mejores para las generaciones futuras, y de ello tiene que estar contenta: puesto que las reformas hechas deprisa casi siempre tienen un éxito infeliz, y disuaden de repetir a los más valientes (Trivulzio, 2011: 83-85).

Estas palabras demuestran que la autora era consciente de la necesidad de revertir la situación de las mujeres en otros ámbitos -no sólo en el educativo-, pero paso a paso, de forma inteligente. Como advierten Fugazza y Rörig, se trataba de una forma de reelaborar algunas de las ideas de Mozzoni, pero "con maggior senso pratico e «intelligente realismo»" (Fugazza-Rörig, 2010: 210).

Cuando las mujeres se instruyan, tendrán más armas para reivindicar otros derechos, pero progresivamente, consiguiéndolos uno a uno, así se evitarían los conflictos con el otro sexo y se tendrían más posibilidades de conquistar la anhelada igualdad, incluso de forma espontánea. Este es, en suma, el pensamiento feminista de Cristina Trivulzio.

Que se eduquen y se instruyan sin ostentación aquellas mujeres que por la naturaleza de su ingenio, y por su estado sientan la necesidad de una cultura intelectual y pueden procurársela. Incluso en medio de los graves pensamientos que hoy afligen a la sociedad italiana, el lento, pero continuo progreso de la mente femenina no pasará inobservado, y quizá antes de lo que yo creo las mujeres obtendrán espontáneamente de los hombres la merecida justicia (Trivulzio, 2011: 87).

Las dos últimas páginas de su ensayo son una clara exhortación a una Italia más justa e igualitaria. La autora imagina el futuro de la nación y apela a la sensatez de los gobernantes. Muestra una actitud esperanzadora, encomendándose al devenir natural de los acontecimientos. 
[...] me parece ver en los hombres que pueden hoy en día dirigir el gobierno de la nación, que la representan, o que se dedican a su defensa y al servicio del país, me parece, digo, ver reducido el deseo de mantener, mediante el sometimiento y la degradación de la mujer, su despótica autoridad sobre la casa y sobre la familia. Me parece verlos asombrados, dándose cuenta de que las mujeres, educadas e instruidas por sus mismos maestros y en los mismos estudios, no renuncian por ello a ser mujeres, a vivir la vida de la mujer, a asumir y cumplir sus obligaciones, no aturden a la sociedad con entusiastas alabanzas de su ingenio, exaltando su excelencia, pidiendo derechos, despreciando obligaciones, y deseando extrañas reformas (Trivulzio, 2011: 89).

Concluye con una declaración que la involucra explícitamente en la querella de las mujeres, reconociéndose como mujer que "ha abierto y preparado el camino" a otras mujeres:

¡Quieran las mujeres felices y honradas de los tiempos futuros dirigir, de vez en cuando, su pensamiento a los dolores y a las humillaciones de las mujeres que las precedieron en la vida, y recordar con algo de gratitud los nombres de aquellas que les abrieron y prepararon el camino a la nunca antes disfrutada, quizá apenas soñada, felicidad! (Trivulzio, 2011:91).

Esta investigación reconoce la labor de Cristina Trivulzio di Belgioioso y la importancia de su pensamiento socialista y feminista, fuente de inspiración, sin duda, de las grandes conquistas de las mujeres a partir de la segunda mitad del siglo XX.

\section{Bibliografía}

AA.VV, Cristina Trivulzio di Belgiojoso. An italian princess in the 19th C. Turkish Countryside, Filippi Editore, Venecia, 2010.
Arriaga Flórez, M., "Cristina Trivulzio di Belgioioso en la Prensa", en Margherita Bernard; Luisa Chierichetti; Mercedes González- Ivana Rota (eds.), Papel de Mujeres. Mujeres de Papel, Sestante, Bérgamo, 2008, pp. 9-20.

Arriaga Flórez, M., "Cristina Trivulzio di Belgiojoso: viaje y exilio", en $\mathrm{M}^{\mathrm{a}}$ Josefa Calvo Montoro-Flavia Cartoni (eds.), El tema del viaje: un recorrido por la lengua y la literatura italiana, Universidad de Castilla La Mancha, 2010, pp. 389-400.

Arriaga Flórez, M., "Planfetarias, espías y cañoneras en la unificación de Italia", en Estela González- Ángeles Cruzado (eds.), Rebeldes literarias, Arcibel, Sevilla, 2010.

Arriaga Flórez, M., "Cristina Trivulzio y la condición de las mujeres", en Mercedes Arriaga Flórez- Estela González de Sande (eds.), Cristina Trivulzio di Belgiojoso. De la presente condición de las mujeres y de su futuro, Arcibel, Sevilla, 2011, pp. 2137.

Cattaneo, C., Epistolario, raccolto e annotato da Rinaldo Caddeo, G. Berbèra, Florencia, 1956.

Fugazza, M. C.- Rörig, K., La prima donna d'Italia. Cristina Trivulzio di Belgiojoso tra politica e giornalismo, Franco Angeli, Milán, 2010.

Guicciardi, E., Cristina di Belgiojoso Trivulzio cent'anni dopo, Milán, 1973.

Guidi, L., Scritture femminili e storia, ClioPress, Nápoles, 2004.

Guidi, L., Vivere la guerra. percorsi biografici e ruoli di genere tra risorgimento e primo conflitto mondiale, ClioPress, Nápoles 2007.

Malvezzi, A., La principessa Cristina di Belgiojoso, 3 vols., Treves, Milán, 19361937. 
Manzoni, A., "Marzo 1821", en Gilberto Lonardi-Paola Azzolini (eds.), Alessandro Manzoni. Tutte le poesie 1797-1872, Marsilio, Venecia, 1987.

Mozzoni, A.M., La donna in faccia al progetto del nuovo Codice civile italiano, Tipografia Sociale, Milán, 1865.

Penna, M., Le donne del Risorgimento, Europa Edizioni, Roma, 2019.

Severgnini, L., La principessa di Belgiojoso: Vita ed opere, Virgilio, 1972.

Trivulzio di Belgioioso, C., Essai sur la formation du dogme catholique, 4 vols. Paris: J. Renouard \& C., 1842.

Trivulzio di Belgioioso, C., "Stato attuale dell'Italia", L'Ausonio, vol. I, 1846, pp. 5-20.

Trivulzio di Belgioioso, C., De la presente condición de las mujeres y de su futuro, edición de Mercedes Arriaga Flórez y Estela González de Sande, Arcibel, Sevilla, 2011.

Trivulzio di Belgioioso, C., Recuerdos del exilio, edición de Estela González de Sande y Pablo García Valdés, Dykinson, Madrid, 2021.

Vercesi, L., La donna che decise il suo destino. Vita controcorrente di Cristina di Belgioioso, Neri Pozza, Venecia, 2021. 
